\title{
LXII. Remarks on a paper by Mr. Dalton on the Chemical Compounds of Azote and Oxygen, \&c.
}

\section{William Higgins Esq.}

To cite this article: William Higgins Esq. (1817) LXII. Remarks on a paper by Mr. Dalton on the Chemical Compounds of Azote and Oxygen, \&c. , Philosophical Magazine Series 1, 49:228, 241-250, DOI: $10.1080 / 14786441708637897$

To link to this article: http://dx.doi.org/10.1080/14786441708637897

册 Published online: 27 Jul 2009.

Submit your article to this journal $[\pi$

Џlll Article views: 1

View related articles $\llbracket$ 


\section{[ 241 ]}

LXII. Remarks on a Paper by Mr. Dacton on the Chemical Compounds of Azote and Oxygen, \&ic. By William HigGINs, Esq.

To Mr. Tilloch.

Sir, - Y ov will oblige me by inserting in your candid and useful Magazine the following remarks on a paper of Mr. Dalton on the Chemical Compounds of Azote and Oxygen, \&c. which appeared in the number of Dr. Thomson's Annals of Philosophy for February.

It is stated that this paper was read before the Literary and Philosophical Society of Manchester in the year 1816. That it should lie by since is not to be wondered at, as containing nothing new; it relates to a hackneyed subject, which chemists have lately gone over repeatedly.

In that part of my paper which appeared in your excellent Magazine for December 1816, I observed that Dr. Thomson stepped forward repeatedly in a very unjust cause, which could never do him credit, as the advocate of Mr. Dalton, while the latter stood silent and trembling at the bar of justice.

In consequence of the ahove observation it was, I suppose, that his friend urged him on with his tale, which is obscurely and contradictorily told ; and I may add evasively and unjustly so, respecting myself. But the sole object was to say something on any part of my system with a view to show his face and a confidence of his innocence, at the same time that no mention should be made of the person whom he so glaringly attempted to injure.

I will now give a very cursory view of this paper, for more is not necessary. "Lavoisier (he says) was the first who ascertained the constituents of the atmosphere, thirty years ago."

Priestley was before Lavoisier in the discovery : but it is of no consequevice, as to my present object, which of them was first or second, except in point of justice, which we should never lose sight of as men or philosophers. But Mr. Dalton goes on, "Lavoisier in consequence of vague and contradictor expressions was not decided whether the oxygen and azote of the atmosphere were mixed only, or chemically united; and as in his table of binary combinations of azote with simple substances no mention is made of atmospheric air being one of them, it is likely he considered it as a simple mixture."

This is puerile : there is no chemical combination of azote and oxygen in the proportion in which they exist in our atmosphere; and were they chemically united, it would be unfit to suppor animal life.

Chaptal comes next. " $\mathrm{He}$ was decisively of opinion that Vol. 49. No. 228. April 1817. Q our 
our atmosphere consisted of a mixture of oxygen and azote. Sir H. Davy considered the constituents of the atmosphere as chemically-united; and his reasons for supposing so are adduced, but must be relinquished as ill founded, \&zc."

Mr. Dalton next alludes to his Essays on the Constitution of mixed Gases, published in 1802 ; containing an hypothesis to explain the uniform diffusion of gases by mechanical means. On this principle, the atmosphere was considered a mixture not a combination of its elements.

Before I proceed any further with Mr. Dalton's paper, I will in a few words mention the prominent features of his hypothesis. He supposes that one gas affords a vacuum in its interstices for a second gas of a different nature from itself, and that each particle of the same gas in the mixture presses only on its kindred particle; so that the pressure of each of the different gases which constituie our atmosphere is independent of the other; not one of them pressing on the other, but all distinctly with one uniform weight rest on the surface of the earth. The same law holds good as to the mixture of other gases.

This is a strange hypothesis, which one cannot well reconcile to common sense. All kinds of gases mix uniformly, and there are many gases whose ultimate divisions are of the same size, and some gases whose ultimate particles are much smaller than others; yet their atmospheres of caloric are often larger. 'The calorific atmospheres of hydrogen are larger than those of oxygen. There are some gases whose atmospheres are of the same size;how then can all gases indiscriminately afford vacant interstices one for the other ?

Suppose two parts of one gas were mixed with twenty parts of another gas,of gas extend their pressure to each other only, when such a number of the particles of the predominating gas must be in their way? It appears to me more reasonable to suppose that under those circumstances the different kinds of particles or their atmospheres, which is the same in effecr, must rest indiscriminately on each other.

Many objections have been made to this hypothesis, and many more might be brought forward were it considered necessary.

I do not make these cursory remarks with a view to completely invalidate this hypothesis, for they are not sufficient to accomplish such an object. My reason for taking any notice of those fanciful conceptions will appear presently. I must say that it is the only part of his NEw System of Chemical Philosophy that he has not borrowed; for the principal and most interesting part was taken from my Comparative $V i \epsilon w$, as had been clearly proved by many, and lately confirmed by my own writings. 
But to return to the subject of atmospheric air and its gases. - Soon after this appeared (meaning his hypothesis of mixed gases) Berthollet, in his Researches into the Laws of Chemical Affinity, announced a new cxplanation on the phænomena of mixed gases. According to this eminent chemist, there are two species of affinity; the one strong, the other weak:-the strong: affinity makes bodies unite chemically; the weak only serves to diffuse them through each other without producing condensation of volume ; its effects may be called solution or dissolution. Of this kind, he conceives, is the mutual action of gases that do not combine, and that it operates just the same upon gases inclined to combination or not:-thus a mixture of carbonic acid gas and hydrogen is subject to this weak or slight affinity just as much as one of oxygen and hydrogen. Something similar to this is supported by Muruy in his Elements of Chemistry, and by $\mathrm{Dr}$. Thomson in the third edition of his Chenistry. $\mathrm{Mr}$. Gough in different papers in the Manchester Memoirs; and in some essays of his in Nicholson's Journal, endeavoured to support the opinion of atmospheric air being a chemical compound; but he does not avail himself of the two affinities of the strong and the weak, in order to explain the phrnomena of mixed gases." Here ends Mr. Dalton's old retail; and had he given a true history one might probably read it without disgust.

The distinction of weak and strong affinity is of considerable importance in Nature, and they should be well understood and defined from each other. What is called weak affinity does not only prevail between permanent gases, but also between those gases and the vapour of water and all other vapours, and even between fuids and solid substances.

I will now prove that I was the first who made this important distinetion between weak and strong affinity twenty-eight years ago. At that distant period I felt doubtful whether the sulphur and hydrogen in sulphuretted hydrogen gas were chemically united or not, from the great facility with which they were separated in a variety of ways. This consideration led to the following remarks, which I quote from page 73 of my Comparative View.

"In my opinion it is mere solution (that is, that the sulphur is held in solution by the hydrogen), such as takes place between the neutral salts and water, the alkalies and water, and sugar and water, \&c. Although the facility with which sulphuretted hydrogen is decomposed favours this hypothesis, yet there are circumstances apparently ngainst it, particularly its condensation in water, and its expulsion from it again by heat without decomposition.

6" Upon what principle this modification of attraction exists Q.2 
between bodies, has not been explained ; and the difference between it and chemical union has never been defined or discriminated by chemists.

"It appears to me that solution, or that power by which water dissolves or condenses carbonic acid gas, pure ammoniacal gas, sulphureous acid gas; and that power by which hydrogen dissolves sulphur and phosphorus; and also that power by which all the gases dissolve water ; and laslly, that by which water dissolves saline bodies, \&c. without changing their nature or properties, is occasioned by a sort of intermediate attraction, not differing much from chemical infuence but in its degrees of force, and not at all different from that power whereby the planets influence each other."

There was an idea entertained about this time, that many fiery meteors were occasioned by the collection and inflammation afterwards by electricity of hydrogen in the upper regions of the atmosphere. This induced me to make the following experiment. I made a mixture of two parts of hydrogen and one of oxygen by measure. With this I filled a jar eighteen inches long and nearly three inches in diameter. This mixture, after having stood in dry quicksilver for nine months, was found to be uniform throughout the whole column; for when a small portion of the lower part was transferred with little or no agitation, it was wholly condensed into water by the electric spark.

The rotundity of a bubble of air, whether simple or mixed, shows a strong influence of its atoms or particles on each other : and probably this influence, as I originally supposed, is occasioned by the gravitation of their solid particles towards each other, particularly as those particles must be in proportion to their diameters removed a considerable distance from each other.

It is remarkable that $\mathrm{Mr}$. Dalton should enumerate the slightest and the most trifling observations of different authors who wrote after me on this subject, and pass over the facts above quoted which must be allowed to be original. He cannot plead as an excuse that he had not read my Comparative View, after what has lately occurred-No, the omission is evidently wilful. I could expect nothing else.

It is said that there is a species of depravity peculiar to human nature-which is, that we hate the person we injure more than any other individual. This is readily accounted for.

The rest of this paper relates to the different chemical combinations with azote and oxygen according to the different proportions in which they unite. He gives the opinion and cxperiments of a great many chemists, who have attempted to prove the quantity of azote and oxygen by weight and measure in the different compounds which those elements are capable of forming. 


\section{on the Chemical Compounds of Azote and Oxygen, 80. 245}

No two of them agree, and he differs a little from them all: but he takes care to adhere to the middle line of difference; for any person intimately acquainted with experimental chemistry will readily perceive, in reading his New System of Philosophy, that he is not an experimenter, notwithstanding what he asserts on that subject : in short, whatever knowledge he possesses is evidently derived from reading the experiments and the writings of others.

I will therefore pass over this contradictory detail, particularly as it is almost in substance what Dr. Thomison advanced in his History of the Atomic Theory in the Encyclopedia Britannica, of which I have already taken notice in this Magazine for November and December 1816.

The only part of it that deserves any attention is what relates to the doctrine of definite proportions, which $M r$. Dalton attempts to explain in his own way; but no mention is made of its original author. On this part he begins thus: "The subject of the greatest difference amongst us is in regard to the absolute weights of the elements azote and oxygen, which combine to form the several compounds. Gay Lussac and most of the other chemists I have mentioned, who follow him as volumists*, contend that the proportions are as under: viz.

$$
\begin{aligned}
& \text { Metsives. Measures. Measures. } \\
& 100 \text { azote }+50 \text { oxygen }=100 \text { nitrous oxide. } \\
& 100 \ldots \ldots+100 \ldots \ldots=200 \text { nitrous gas. } \\
& 100 \ldots \ldots+150 \ldots \ldots=\text { subnitrous acid. } \\
& 100 \ldots .+200 \ldots \ldots=100 \text { nitrous acid gas. } \\
& 100 \ldots+250 \ldots \ldots=\text { nitric acid. }
\end{aligned}
$$

The foregoing proportions are pretty correct, as shall be shown presently.

"But (continues Mr. Dalton) from the views I entertain on the subject as derived from experiments, the true portions of

* My Comparative View was published twenty year' before Mr. Dalton's New System of Philosoplyy appenred, and Gay Jussac had written some time after hin. It will be found by any person who will take the pains of carefully perusing my work, thac 1 was perfectly acquainted with the proportions in which gases combine in volumes; it was the ground-work, together with their specilic gravities, on which my entire system rested: and without this knowledge no luman being conld at tempt to estimate the different proportions in which they unite particle to particle; and much less the relative size, and of course the relative weight, of those parcicles; for the specific weight of the ultimate divisions of all kinds of ponderable matter is the same-their size or diameter only constitutes the difference.

Withont a previous knowledge of the foregoing principles, we might as well attempt to ascertain the weight of the most distant fixed stars, as those of particles, atoms, or molecules of matter: hence it is evident that the above passage of his operates more against Mr. Dalton than any thing that could be brought forward. 
the compounds would be more nearly stated as under." Then his table of measures of the proportions in which the two gases unite, and symbols to represent their atoms, are given. I shall content myself at present by describing those proportions of atoms and measures, beginning with the nitrous oxide, as containing the smallest proportion of oxygen.

$\mathrm{Mr}$. Dalton, wishing to differ from every body else, states that 100 of azote and 60 measures of oxygen enter into the constitution of nitrous oxide; and he represents the compound atom as consisting of two ultimate particles of azote and one ultimate particle of oxygen. Now it has been shown by Sir H. Davy and by myself, in a variety of ways, a good many years ago, that this gas consists of one volume of azote and half a volume of oxygen; and as each particle of the azotic gas was supplied with a particle of oxygen, I inferred that the half volume of oxygen contained as many divisions as one volume of azote, on the same principle that one volume of oxygen contains the same number of divisions that the two volumes of hydrogen do. I also inferred that the ultinate particles of azote are nearly twice the size and of course twice the weight of those of oxygen, although the latter gas is somewhat heavier. The specific gravity of gases, as I have long since proved in my Comparative View, does not always indicate the real weight of their ultimate particles or atoms; and this circumstance has led chemists into many blunders, particularly those who have attempted to ascertain the weight of atoms and molecules on the principle of my definite proportions.

But to return to the gaseous oxide.-It would require 200 measures of azote in the place of 100 , to supply the atoms of this gas with twoultimate particles of azote; and the ten measures of oxygen which he has thrown in, by way of showing the accuracy of his philosophy, are quite superfluous.

I consider azote, like almost all substances that unite to oxygen, as an inflammable base; and an ultimate particle of oxygen never unites to two ultimate particles of any inflammable base: while the reverse is the constant law of nature, as 1 particularly demonstrated throughout the whole of my Comparative View, and $I$ have laid great stress lately on the importance of this law in my Alomic Theory and Electrical Phanomena.

Next in regular order comes nitrous gas.-He allows this gas 100 of azote and 124 of oxygen by measure, and its atom is represented as one of azote and one of oxygen. 104) measures of oxygen would give every ultimate particle, in 100 of azote two ultimate particles, so as to form an atom of nitrous gas; therefore, according to Mr. Dalton's atom, 74 measures of oxygen remain unaccounted for. 
Agreeably to my experience, nitrous gas consists of one measure of azote and one of oxygen, and the latter affords two particles to every one of the former so as to constitute an atom.

When nitrous gas and nitrous oxide are mixed, they only diffuse through each other mechanically; for the nitrous gas retains its second particle of oxygen with as great force as the other gas can attract it-therefore no change can be produced. None of those gases possess an acid property.

The third compound of those elements is called subnitrous acid: it is what I distinguished in my Comparative View by the name red nitrous acid, from its red colour. This acid according to Mr. Dalton consists of 100 of azote and 186 of oxygen by measure, and the atom is represented by his diagram or symbol as consisting of three ultimate particles of oxygen and two of azote. Let us examine those proportions :- In the first place, 150 measures of oxygen would supply every particle in 100 of azote with three particles of oxygen; there remains therefore a surplus of 36 measures of oxygen. As to the second particle of azote, I cannot conceive whence it came or how supplied, unless indeed the atons were cloven in two.

This acid, according to my experiments, contains one measure and a half of oxygen and one of azote; and the atom, as represented in my Comparative View, consists of one particle of azote and three of oxygen. It is diffcult to obtain this a acid pure; that is, free from the pale or straw-coloured nitrous acid which will be described presently. It is obtained in a tolerable degree of purity when nitrous gas is mixed in excess with atmospheric air, or when nitrous gas is passed into nitric acid until it is incapable of receiving any more. This acid can exist in the gaseous state when excluded from water.

The next and fourth compound is distinguished by the name of nitrous acid gas by some modern chemists. I called it in my Comparative View, pale or straw-coloured nitrous acid, from its colour. Mr. Dalton supposes this acid to consist of 100 of azote and 248 of oxygen by measure. The 200 alone, laying aside the 48 measures of oxygen, would supply every particle of the azote with four particles of oxygen; and yet, to my very great stirprise, Mr. Dalton's symbol represents the atom of this acid as consisting of one particle of azote and two of oxygen, the proportions which the atom of nitrous gas contains.

In my Comparative View I represented the atom of this acid, by means of a diagram, as consisting of one particle of azote and four of oxygen.

It is very difficult to obtain this acid pure; for in the common way of distillation it comes over with more or less of red nitrous acid, or with a mixture of nitric acid. This acid is produced by Q 4 mixing 
mixing two measures of nitrous gas with one of oxygen. This shows that the one measure of oxygen contains twice as many particles as there are atoms in two measures of nitrous gas. This was one of the many facts which led me originally to the doctrine of definite proportions-that beautiful law by which oxygen unites to bodies in different doses, and that the $2 \mathrm{~d}, 3 \mathrm{~d}, 4 \mathrm{th}$, and 5 th were all distinct multiples of the first or minimum dose.

In producing the pale nitrous acid by mixing oxygen and nitrous gas, there are sometimes formed atoms of the red nitrous acid mixed with the pale, therefore less oxygen is consumed; and again, particles of nitric acid are formed, which demand more oxygen, and which only mix with the pale; -in these cases different quantities of oxygen are consumed by the nitrous gas. The foregoing variations depend upon the manner in which the gases are mixed, and the surface which they present to water.

These facts will account for the difference of opinion entertained by chemists respecting the proportions in which the two gases unite so as to form, according to them, the same acid.

The fifth and last combination of those elements is the nitric, which I called in my Comparative View the colourless nitrous acid, as being when perfectly pure as limpid as distilled water.

Mr. Dalton represents this as composed of 100 measures of azote and 310 of oxygen: this quantity should give more than six ultimate particles of oxygen to each particle of the azote. His symbol gives only five, with the extraordinary proportion of two of azote :- whence comes the second particle of azote is best known to Mr. Dalton himself; I cannot make it out, I must own.

In my Comparative View I represented the atoms of this acid as consisting of one particle of azote and five of oxygen. My definite proportions of the different compounds which those elements are capable of forming, are as follow :

$\begin{array}{llll}\text { Nitrous oxide } & \ldots & \ldots & 1 \text { and } 1 . \\ \text { Nitrous gas } & \ldots & \ldots & 1 \text { and } 2 . \\ \text { Red nitrous acid } . . & \ldots & 1 \text { and } 3 . \\ \text { Pale nitrous acid } \ldots & \ldots & 1 \text { and } 4 . \\ \text { Nitric acid } & \ldots & \ldots & 1 \text { and } 5 .\end{array}$

The variation of the different forees of attraction according to the quantum of oxygen was also stated, which is the most important part of the whole system, and which alone could enable me to account for the following facts; viz,

1 and 1 will have no effect on $I$ and 2.

1 and 2 will not affect .. 1 and 3 .

1 and 3 no effect on .. $\quad . . \quad 1$ and 4 .

1 and 4 no effect on .. .. 1 and 5 .

They will only mix mechanically. 
On the other hand, in the following order they will have a chemical action on each other, so as to produce a partial decomposition.

1 and 2 will take one portion of its oxygen from 1 and 4 , and 1 and 3 will be produced between them both.

1 and 3 will also deprive 1 and 5 of one portion of its oxygen, and $I$ and 4 will be the result.

The foregoing facts are founded on experiments, and they prove that my proportions are indisputably correct.

I will here make one remark on Mr. Dalton's symbols ; - that is, he unites my $\mathrm{l}$ and $\mathrm{l}$ to $\mathrm{my} \mathrm{l}$ and 2 to form an atom of red nitrous acid, and my 1 and 2 with $l$ and 3 to form an atom of nitric acid. Now these atoms are incapable of uniting chemically, as I stated above.

Considering that those distinctions of the definite proportions in which azote and oxygen unite to form the foregoing difierent compounds originated with me, as had been often stated, and which facts and dates render as clear as possible, it is really extraordinary that $\mathrm{Mr}$. Dalton should not even mention my name in treating on this small part of my system, were I ever so wrong in my calculation. But the wonder will cease when it is considered that he brings forward as his own my diagrams, which represent the proportions in which the particles of the different elements unite so as to form distinct atoms, in a mutilated and discordant state in the form of symbols, in order to disguise them from the original. But what is still worse, in those symbols of his, monstrous proportions are represented, which Nature never produced.

I am inclined to think that Mr.Dalton himself, after what has passed respecting him and me, and after three or four years silence on the subject, would never come forward with bis old song so wretchedly set to music,-if such I can call his symbols, without making some apology for what has lately passed on the subject of the atomic theory. It must be a ruse de guerre of one of his friends, and I strongly suspect who the person is; but as Mr. Dalton's name is to the paper, and no doult with his consent, he alone should be addressed. It is rery much to be lamented that science should be infested with such juggling.

There are at present a certain number of writers on chemistry, who, to the disgrace of the nineteenth century, make it a common practice to play into each other's hands, and to deprive men of superior talents and information of the originality of their discoveries; and should it happen that they cannot take immediate possession of them, they pass them by unnoticed in their compilations until a more favourable opportunity offers. This shame- 
ful conduct must, and has already injured the cause of science: for to my own knowledge many excellent experimenters have retired from their labours in disgust. I have the same feeling; but from my situation as professm to one of the first institutions in Europe, I must continue to fight my war; not for myself so much as for the cause of science, for I have already established my original claim.

I have many to oppose, but with justice at my back I feel myself equal to them all. Perfect security of every species of property, whether it be scientific or otherwise, is thegreat spur to industry; and this sacred security once removed, farewell to all human efforts!

$$
\text { I am, sir, }
$$

Your very humble servant,

Dublin Society, March 22, 1817.

WM. Higgins.

LXIII. Answers to the Geological Queries by N.J.Wrnch, Esg. yith some Romarks, and further Queries proposed to that Gentleman, and to other practical Investigators of the Strata of the North of England. By A CorresposDent.

\section{To Mr. Tilloch.}

Sir, - I BBg to tender my best thanks to Mr. Winch for the new facts regarding the interesting Stratification of Northumberland, Durham, Yorkshire, and Cumberland, which he has furmished pp. 207 and 208 of your last Number; being willing and anxious to consider these, as preludes to much more numerous and precise local facts, in answer to my several Queries in p. 122 \&ic.; part of which, Mr. W. might now, perhaps, furnish from his Notes, or will ere long, from inquiry or inspection of the spots, be ahe, it is hoped, to furnish, and which I will still rely on his kindness to do, and hasten to return the best answers in my power, to his two queries in p. $20 \mathrm{~S}$.

lst. I certainly consider, as I have understood Mr. Smith, Mr.Farey (P.M. xxxix. p. 256, and xliii. p. 256 \&c.) and many others to do, the Alum-shale series and irregularly thin Coalseries on it, in the north-east of Yorkshire, to be included in the assemblage of Strata, of an argillaceous character principally, which Mr. Smith, its discoverer, found it convenient, and without any theoretic views to designate the "Clunch Clay;"-I decline for obvious reasons entering into the discussion of "distinct formations;" where "Doctors disagree," practical Men, in search of facts and useful truths only, had better keep aloof. 